\title{
Response of a Coastal Plume Formed by Tidally Modulated Estuarine Outflow to Light Upwelling-Favorable Wind
}

\author{
AleXANDER E. YANKOVSKY AND GeORGE Voulgaris \\ School of the Earth, Ocean and Environment, University of South Carolina, Columbia, South Carolina
}

(Manuscript received 18 June 2018, in final form 29 December 2018)

\begin{abstract}
This study presents observations of a buoyant plume off Winyah Bay, South Carolina, which was formed under conditions of high freshwater discharge and upwelling-favorable wind forcing. Analysis of observations demonstrates that the response of the anticyclonic bulge formed by tidally modulated estuarine outflow to the light upwelling-favorable wind is more complex than the previously studied far-field response. The latter can be described by a slab-like model with mixing concentrating at the offshore edge of a buoyant layer. The observed plume depth increased from $\sim 3 \mathrm{~m}$ near the mouth to $6 \mathrm{~m}$ at the offshore edge, with plume depth changing in a steplike fashion rather than continuously. CTD profiles near these steps revealed overturning indicative of vigorous mixing. Estimates of the gradient Richardson number confirmed the likelihood of mixing/entrainment not only at the offshore edge of the plume but also in the proximity of the observed steps. We hypothesize that these steps represent tidal fronts that undergo geostrophic adjustment and are advected offshore by the superimposed Ekman drift. Scaling analysis suggests that mixing and entrainment at the observed interior fronts can be enhanced by superposition of geostrophic and wind-induced shear.
\end{abstract}

\section{Introduction}

Riverine discharge delivered into the coastal ocean is subject to mixing with oceanic water both because of the inherent dynamics of a buoyant outflow and because of the action of tidal and wind forcing. The intensity of mixing determines density distribution and ultimately flow patterns in the coastal ocean, as well as dispersion of sediments, pollutants, and nutrients carried by a river. Both numerical modeling (e.g., Xing and Davies 1999; Whitney and Garvine 2005) and observational (e.g., Münchow and Garvine 1993; Houghton et al. 2004; Lentz and Largier 2006) studies found that mixing between the oceanic and riverine waters is more effective under upwelling-favorable wind forcing. In such a case, the offshore Ekman drift transports buoyant water well beyond the seaward limit of an unforced plume and can cause a complete detachment of the buoyant layer from the coast. As the plume spreads offshore, its surface area exposed to the wind stress increases, making it potentially more susceptible to wind-induced mixing.

A two-dimensional theory describing the evolution of a plume exposed to upwelling-favorable wind stress

Corresponding author: Alexander E. Yankovsky, ayankovsky@ geol.sc.edu was formulated by Fong and Geyer (2001, hereafter FG01) and further developed by Lentz (2004, hereafter L04). The theory assumes that mixing across the pycnocline in a preexisting plume exposed to an onset of wind stress is controlled by the bulk Richardson number $\left(\mathrm{Ri}^{*}\right)$,

$$
\mathrm{Ri}^{*}=\frac{g \Delta \rho h}{\rho_{0}(\Delta u)^{2}}
$$

where $\rho_{0}$ is the reference (ambient) seawater density; $\Delta \rho$ is the density anomaly associated with a buoyant layer; $h$ and $\Delta u$ are the buoyant-layer depth and velocity anomaly, respectively; and $g$ is the acceleration due to gravity (e.g., L04). Mixing primarily occurs in the offshore edge of the plume, where the pycnocline outcrops to the surface and $\mathrm{Ri}^{*}$ drops below its critical value of $\sim 0.5-1$ because of the decreasing depth of the plume. It is also assumed that because of rapid lateral homogenization the plume has spatially constant $\Delta \rho$ and, except for the offshore edge, $h$, corresponding to nearcritical Ri*. As time progresses, $\Delta \rho$ decreases, whereas $h$ increases because of ongoing mixing. The theory was first tested with idealized numerical simulations in FG01 and then was confirmed by observations (e.g., L04; Houghton et al. 2004). 


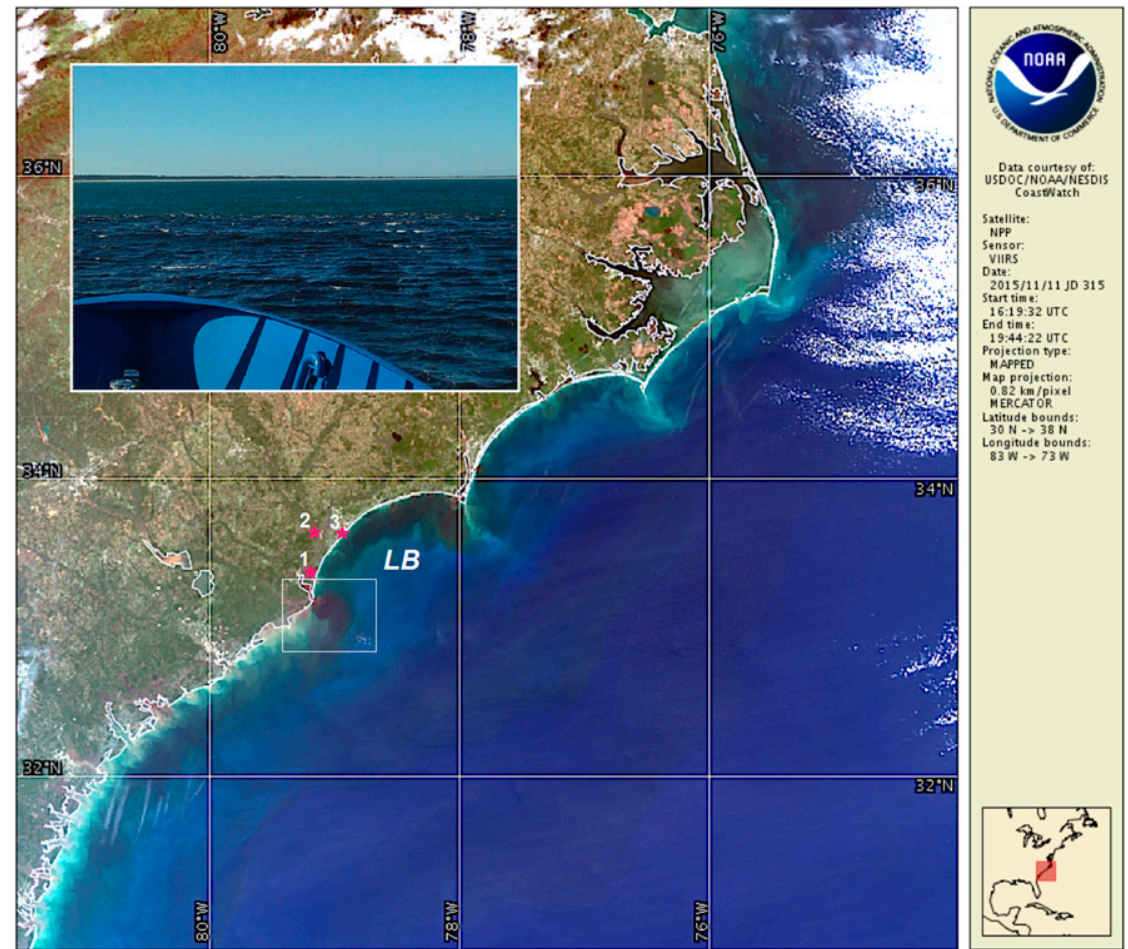

FIG. 1. True-color satellite image of the northern SAB obtained on 11 Nov 2015. The white box shows the study area (image from NOAA CoastWatch; https://coastwatch.chesapeakebay. noaa.gov). $\mathrm{LB}=$ Long Bay; purple stars are the locations of time series: 1) NOAA 8662245, 2) USGS 02135200, and 3) NOAA 8661070. Inset is a photo of the front between hydrographic stations $\mathrm{U} 1$ and $\mathrm{U} 2$.

However, this theory focuses on the far field of a plume and does not consider the coastal source of buoyant water feeding the plume: adding the buoyant water discharge will violate the assumption of spatially constant $\Delta \rho$. To add complexity, the buoyant outflow from an estuary is often tidally modulated, with the formation of a tidal plume front in the proximity of the estuarine mouth. In the absence of wind forcing, the tidal front is invigorated at the same location following each tidal cycle (typically with 12.4-h periodicity) and acts as a hot spot for turbulent mixing (e.g., Orton and Jay 2005; MacDonald et al. 2007; O'Donnell 2010; Horner-Devine et al. 2015). In addition to a tidal front residing within the larger-scale buoyant bulge, multiple interior fronts can develop behind the leading front because of shear-induced mixing and dilution of the buoyant layer (e.g., Garvine 1984) or because of temporal nontidal variations of the buoyant discharge (Luketina and Imberger 1987). This study addresses the question of how superimposed Ekman dynamics associated with the upwelling-favorable wind interacts with some of these interior fronts found in the near field and bulge area of a plume.

In this paper, we present shipboard observations of a coastal plume off Winyah Bay (WB), South Carolina, a partially mixed estuary in the South Atlantic Bight (SAB; Fig. 1). The upwelling-favorable wind was light while the freshwater discharge was high, implying the formation of a well-pronounced buoyant plume whose intrinsic dynamics were not completely overwhelmed by the wind forcing. The survey focused on the bulge region adjacent to the WB mouth. The freshwater was delivered into the coastal ocean with ebbing tides, and this process was captured by the survey. The rest of the paper is organized as follows: section 2 describes the observational data and their processing, section 3 presents observations and the results of their analysis, and section 4 offers some theoretical considerations and scaling analysis for the interpretation of the observed features, while section 5 summarizes the paper.

\section{Observations}

The shipboard survey was conducted by the R/V Savannah on 10-11 November 2015 and consisted of three transects $(\mathrm{A}, \mathrm{B}$, and $\mathrm{C})$ running radially from the $\mathrm{WB}$ mouth (Fig. 2). Each station on transects A and B was occupied twice at a 6-h time interval to allow phase averaging of semidiurnal tidal species (e.g., Wu et al. 2013). 


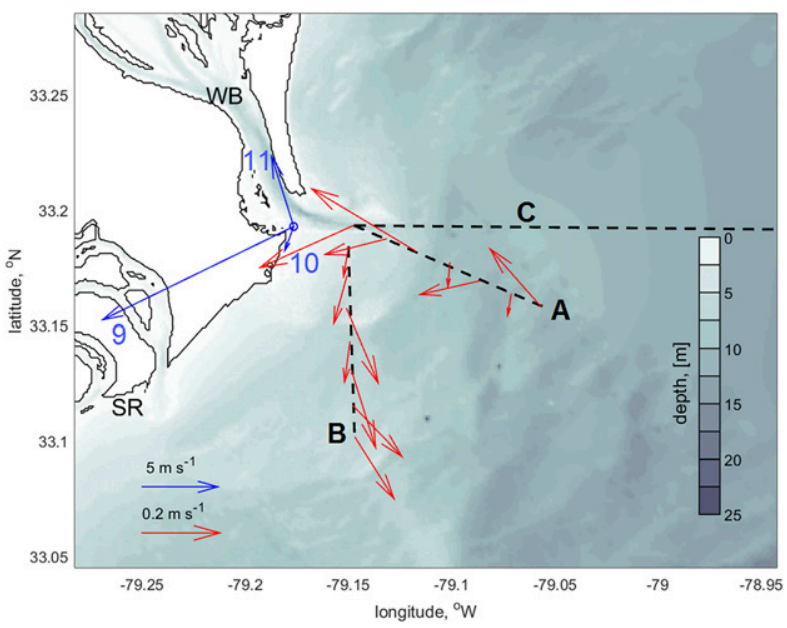

FIG. 2. Bathymetry of the study area. Blue circle is the site of meteorological measurements. Blue and red vectors show the daily averaged wind and phase-averaged barotropic currents, respectively. Numbers by wind vectors are days of November 2015; WB = Winyah Bay, SR = Santee River; dashed lines are hydrographic transects.

Several additional stations (denoted as $\mathrm{U}$ and $\mathrm{S}$ ) were occupied between the transect surveys with the purpose of a better demarcation of the buoyant plume. The survey was performed in the following order: $\mathrm{A}_{\mathrm{I}}-\mathrm{U}_{-}$ $\mathrm{A}_{\mathrm{II}}-\mathrm{B}_{\mathrm{I}}-\mathrm{S}-\mathrm{B}_{\mathrm{II}}-\mathrm{C}$ and proceeded in the outward direction from the mouth along transects A, B, and C. Here, I and II refer to the first and second passing of a transect, respectively. The observations comprised downwardlooking $1200-\mathrm{kHz}$ ADCP and CTD measurements. For each station, ADCP data averaging started from the time when ship speed relative to the bottom fell below the prescribed value (typically, $0.5 \mathrm{~m} \mathrm{~s}^{-1}$, but on several occasions this threshold was slightly raised). The averaging continued for $5 \mathrm{~min}$ or until the ship speed relative to the bottom exceeded $1 \mathrm{~m} \mathrm{~s}^{-1}$ (i.e., three stations took less than $5 \mathrm{~min}$ to complete). This averaging procedure yielded high-quality data in the uppermost ADCP bin, which is referenced at $3.05 \mathrm{~m}$ below the surface. The depth of subsequent bins incrementally increases by $0.5 \mathrm{~m}$. The nominal station time was determined as the midpoint in the ADCP time averaging, and the corresponding coordinates from ship GPS were assigned as station coordinates. The CTD data were sampled at 0.25 -s interval and the CTD probe was lowered at $0.2-0.4 \mathrm{~m} \mathrm{~s}^{-1}$, but the actual rate of descent slightly fluctuated around these values because of the ship's roll. The CTD downcast data were averaged in 1-s bins. In analyzing vector quantities, a standard Cartesian coordinate system was applied with $x, y$, and $z$ coordinate axes pointing eastward, northward, and upward, respectively.
Auxiliary data used in this study include wind, river discharge, and coastal sea level measurements. The sea level data are from the NOAA tide gauge stations 8662245 Oyster Landing in the North Inlet Estuary ( $\sim 17 \mathrm{~km}$ northward from the WB mouth) and 8661070 Springmaid Pier on the exposed coast ( $\sim 56 \mathrm{~km}$ northeastward from the WB mouth; Fig. 1). The freshwater runoff into WB is approximated by the USGS discharge measurements at station 02135200 Pee Dee River at Highway 701 near Bucksport, South Carolina (Fig. 1). The atmospheric forcing measurements were obtained from a tower in the WB mouth (Fig. 2).

\section{Results}

A remotely sensed image of the Carolinas' coast (Fig. 1) shows the presence of high-turbidity waters nearshore (light color), likely associated with the energetic wind event preceding the survey. In addition, the dark (brown-purple) color indicates freshwater with a high concentration of organic matter delivered by coastal plain blackwater rivers (Meyer 1990). A welldefined buoyant plume with a sharp front resided in the study area by the end of the survey, when the image was obtained. The interpretation of a dark color as plume water is confirmed by in situ data: The photo in the Fig. 1 inset was taken when the R/V Savannah was approaching the front, sailing from the plume into the ambient coastal water on the NW heading (with the WB mouth on her portside quarter). The dark-blue water with white capping in the foreground is the WB plume.

Wind vectors referenced at noon (hereinafter, all times are UTC) and averaged over the previous $24 \mathrm{~h}$ for 3 days show that wind changed from strong downwelling favorable (averaging $13.7 \mathrm{~m} \mathrm{~s}^{-1}$ ) before the survey (9 November) to light upwelling favorable $\left(\sim 5 \mathrm{~m} \mathrm{~s}^{-1}\right)$ during the survey, on 11 November (Fig. 2). The transition occurred in the second half of 9 November through early hours of 10 November and is evident in the small averaged vector for 10 November. Time series of wind stress components (Fig. 3a) show that the meridional component $\tau_{y}$ (primarily responsible for the cross-shore Ekman drift) became positive (upwelling favorable) approximately $10 \mathrm{~h}$ before the survey, and its magnitude did not exceed $0.05 \mathrm{~Pa}$ throughout the observations. From the wind-forcing temporal pattern, we infer that the observed plume was formed by the WB runoff on 10-11 November, while freshwater discharged earlier was likely to be transported downstream and dispersed by the strong downwelling wind event.

NOAA tidal harmonic analysis (Fig. 3b) shows that tides in the study area are predominantly semidiurnal (also see Blanton et al. 2004). Therefore, phase averaging 


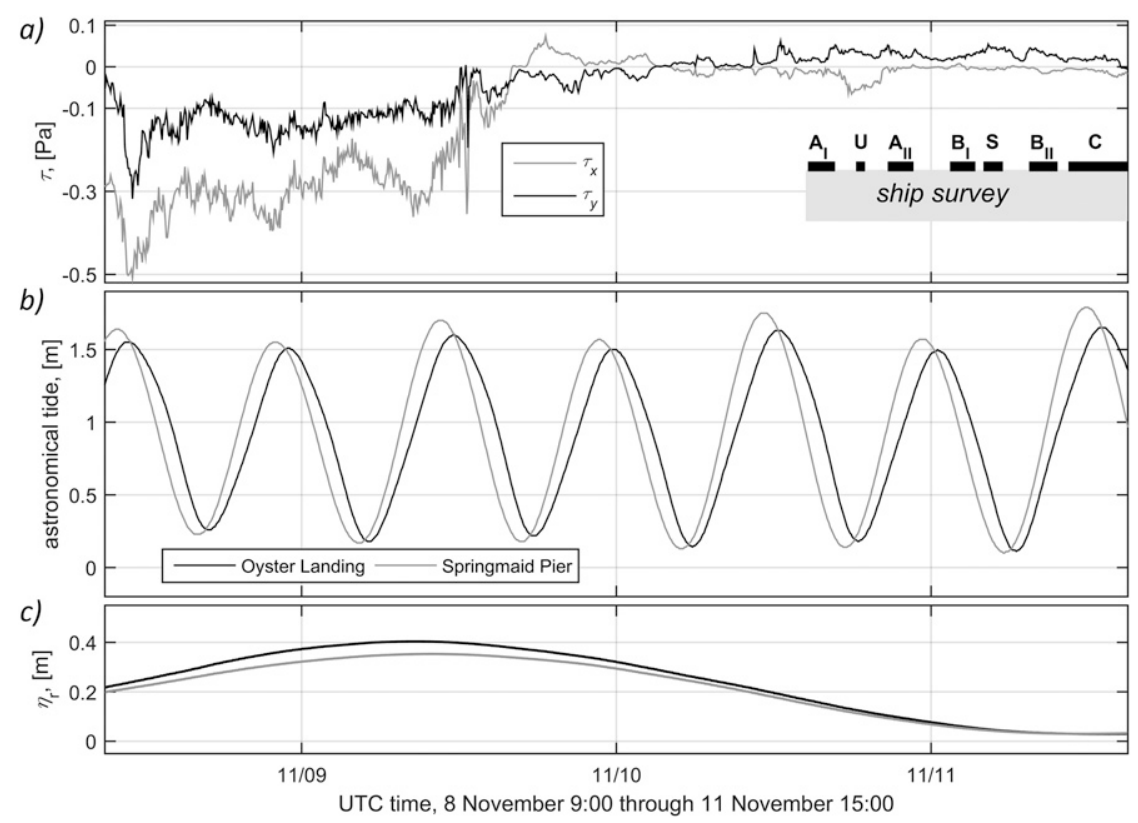

FIG. 3. (a) Time series of eastward (x) and northward (y) components of the wind stress $\tau$, (b) harmonic tidal sea level oscillations at the Oyster Landing and Springmaid Pier NOAA tide gauge stations, and (c) low-pass-filtered residual sea level oscillations at Oyster Landing and Springmaid Pier stations. Periods of shipboard observations and individual transects are shown as gray and black bars, respectively, in (a).

with 6-h sampling lag should significantly reduce the tidal signal, at least in the barotropic (depth averaged) velocity component. Alongshore phase variations in semidiurnal tidal species in the study area are small (Blanton et al. 2004), and the phase lag of free surface tidal oscillations at Oyster Landing relative to Springmaid Pier is due to the location of the former in the tidal creek (delayed signal) versus the latter on the exposed ocean beach. Depth- and phase-averaged currents from transects A and B (Fig. 2) reveal a vortical cyclonic flow pattern at the WB mouth, which is typical for the relaxation of coastal circulation following a strong wind event (e.g., Sanay et al. 2008). This observed flow pattern is also reminiscent of modeling results by Chen et al. (1999) for circulation near Cape Fear in the South Atlantic Bight driven by the tidal and buoyancy forcing only, but without an upwellingfavorable wind (their Fig. 7c). Furthermore, the low-passfiltered sea level anomaly $\eta_{r}$ (Fig. 3c) shows that $\eta_{r}$ had not yet become negative (corresponding to the upwelling event) through the end of our survey. Both the velocity field and $\eta_{r}$ imply that the upwelling-favorable wind event was not sufficiently strong or long lasting to set up a geostrophically balanced northward flow typical of the fully developed upwelling regime (e.g., Yankovsky 2003; Chant et al. 2004).

The tidally averaged freshwater discharge at USGS station 02135200 was steadily growing prior to the shipboard survey and exceeded $750 \mathrm{~m}^{3} \mathrm{~s}^{-1}$ on 9 November (Fig. 4). In fact, the rapid growth of discharge completely suppressed tidal oscillations of streamflow at the site of measurement by the beginning of the shipboard survey. The actual freshwater input into WB was higher because of the contribution of other tributaries (e.g., Kim and Voulgaris 2005), although the Pee Dee River discharge constitutes by far the largest fraction. The second largest river running off into WB is the Waccamaw River, and its discharge at Conway Marina, USGS 02110704 (not shown), prior to the survey averaged to $\sim 150 \mathrm{~m}^{3} \mathrm{~s}^{-1}$. However, downstream of this USGS site, a significant fraction of the Waccamaw River discharge is diverted to the Atlantic Intracoastal Waterway north of WB through an artificial canal, so that the exact amount of freshwater running into WB was unknown.

The near-surface salinity map (Fig. 5) reveals the formation and growth of an anticyclonic bulge through the course of the shipboard survey. No low-salinity water was found on transect $A_{I}$ (with the exception of station $\mathrm{A} 1$ at the WB mouth). Transect $\mathrm{A}_{\mathrm{II}}$ was conducted following the ebb, and the surface salinity at A1 was the lowest $(\sim 14)$ through the whole survey. Newly discharged water propagated in the northeast direction (as revealed by station U1), forming a very sharp front in the northern segment of the plume. This front was 


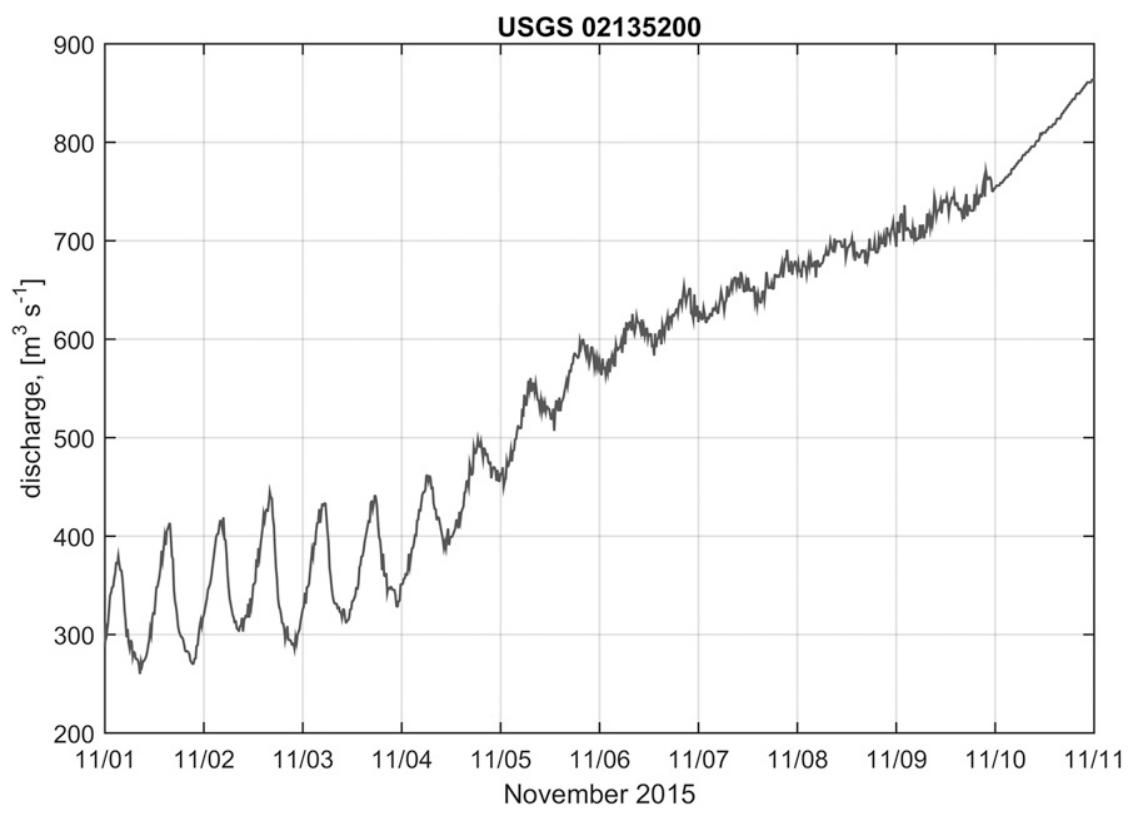

FIG. 4. Instantaneous freshwater discharge measured at USGS 02135200 Pee Dee River at Highway 701 near Bucksport.

characterized by a surface salinity difference between stations U1 and U2 (Fig. 5), which exceeded 17 and could be visually identified. An example is shown in the inset photo (Fig. 1) taken as R/V Savannah was sailing from U1 toward U2. Subsequent geostrophic adjustment of the buoyant outflow resulted in an anticyclonic circulation around the outer part of the plume. Consistent with this anticyclonic flow pattern, salinity on transects $A_{I I}, B_{I}$, and $B_{I I}$ decreased with radial distance $r$, indicating advection of buoyant water southward along the rim of the plume (against the wind stress direction) rather than a radial spreading from the mouth

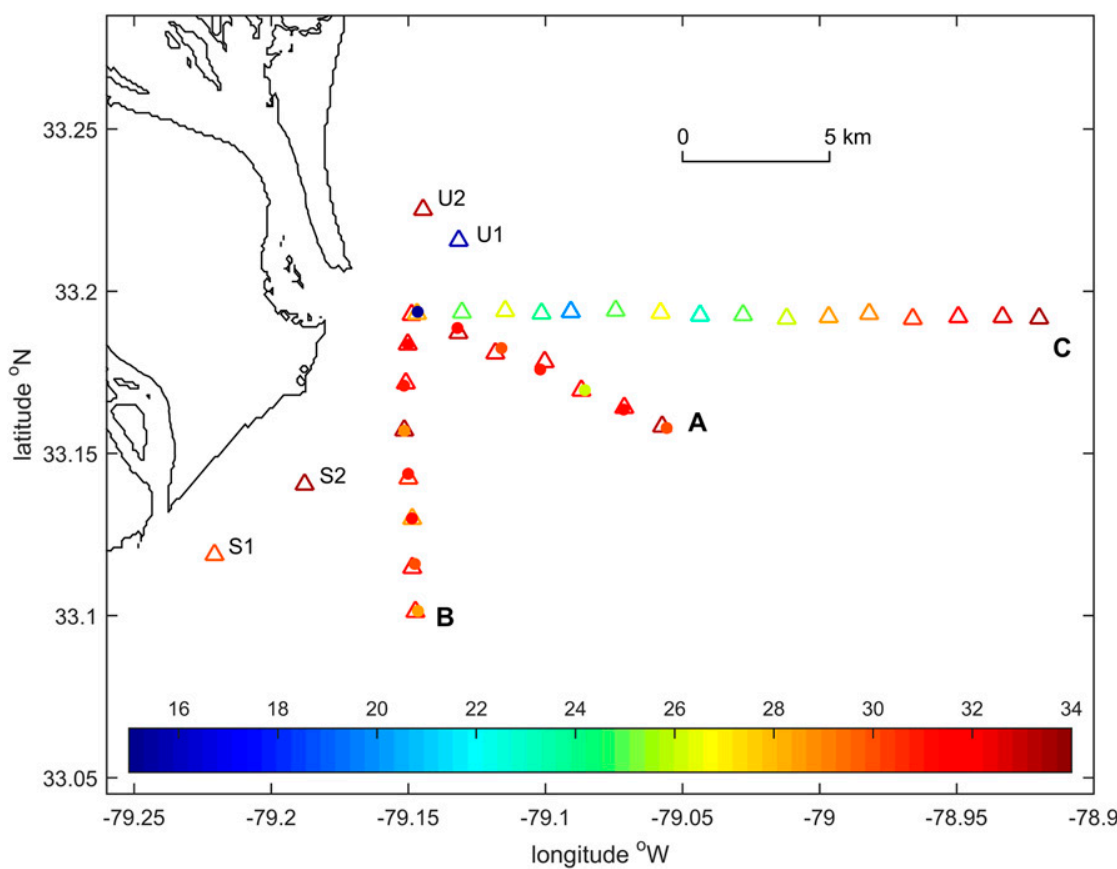

FIG. 5. Near-surface salinity map. Dots indicate data from the repeated (phase averaging) stations along transects $\mathrm{A}_{\mathrm{II}}$ and $\mathrm{B}_{\mathrm{II}}$. 


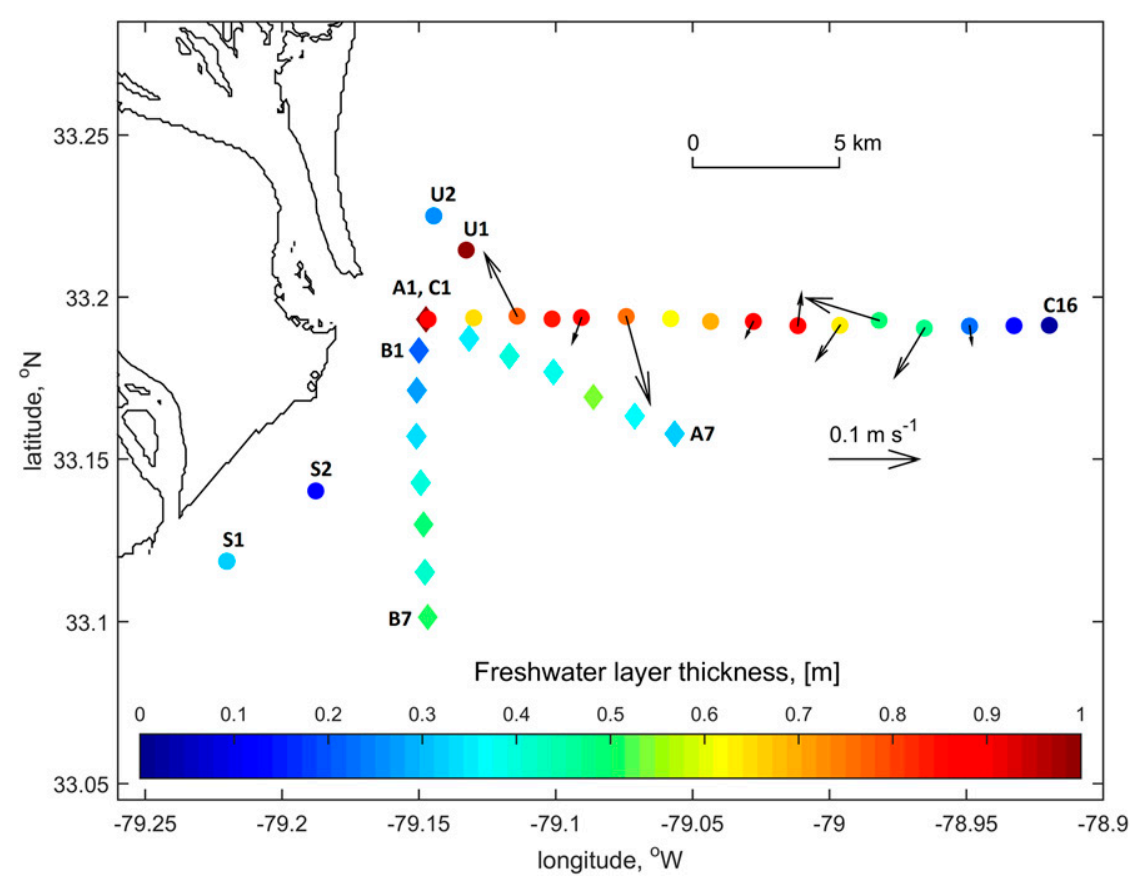

FIG. 6. Spatial distribution of the freshwater layer thickness $h_{f}$. Diamonds and dots are phaseaverage and instantaneous values, respectively. Vectors show the plume's relative velocity defined as the difference between two-bin averaged velocity vectors above and below the 33 isohaline.

typical of nonrotational plumes (e.g., Garvine 1984; O'Donnell 2010).

We characterize freshwater spreading from the mouth by the freshwater layer thickness $h_{f}$ defined as

$$
h_{f}=\int_{-D}^{0} \frac{s_{r}-s}{s_{r}} d z
$$

where $s$ is the salinity, $s_{r}=34.4$ is the reference salinity (as defined by the offshore CTD measurements), $z$ is the vertical coordinate (positive upward), and $D$ is the total water depth. Salinity is extrapolated to the surface at a constant value of the uppermost CTD bin. For transects $\mathrm{A}$ and $\mathrm{B}, h_{f}$ is phase averaged, while for the rest of the stations it is instantaneous (Fig. 6). The largest $h_{f}$ exceeding $1 \mathrm{~m}$ was observed near (station A1) and to the northeast (station U1) of the mouth, consistent with the upwelling-favorable wind stress. Apart from the mouth, other stations nearest to the coast (U2, S1, S2, $\mathrm{B} 1, \mathrm{~B} 2)$ revealed very small amounts of freshwater (Fig. 6), suggesting that almost all the freshwater was trapped in the buoyant bulge offshore. The amount of freshwater in the bulge continuously increased as the survey progressed: Outer stations on transect B show higher values of $h_{f}$ compared to transect $\mathrm{A}$ (which was conducted earlier), although stations B are farther from the mouth than corresponding numbers of stations A. Transect $\mathrm{C}$ (the latest) shows the highest amount of freshwater, which extends offshore for $\sim 20 \mathrm{~km}$ (Fig. 6).

Initially, freshwater spreads to the northeast from the mouth as evident from a high value of $h_{f}$ at station U1. However, subsequently, anticyclonic circulation in the bulge developed, resulting in the southward flow of buoyant water on transect $C$, against the prevailing wind stress. This tendency is demonstrated by calculating the plume's relative velocity $\Delta \mathbf{v}=\mathbf{v}_{1}-\mathbf{v}_{2}$ (Fig. 6), where $\mathbf{v}$ is the horizontal velocity vector, while indices 1 and 2 refer to the two-bin averaged velocity above and below the pycnocline (defined as the 33 isohaline), respectively. Not all stations yielded this velocity estimate, because at some locations only one or no ADCP bins were available above the 33 isohaline (i.e., nearshore stations with shallow pycnocline or offshore edge of the plume where the pycnocline outcropped). In addition, if the pycnocline was deeper than $0.5 \mathrm{D}$, the estimate was discarded because the velocity shear could be strongly affected by the bottom boundary layer associated with tidal currents. Overall, $\Delta \mathbf{v}$ shows a tendency for anticyclonic circulation in the bulge (e.g., northward inshore and southward offshore) but there are noticeable perturbations in both $\Delta \mathbf{v}$ and $h_{f}$ distributions on transect C. A near-perfect crescent-shaped plume of a dark, almost 

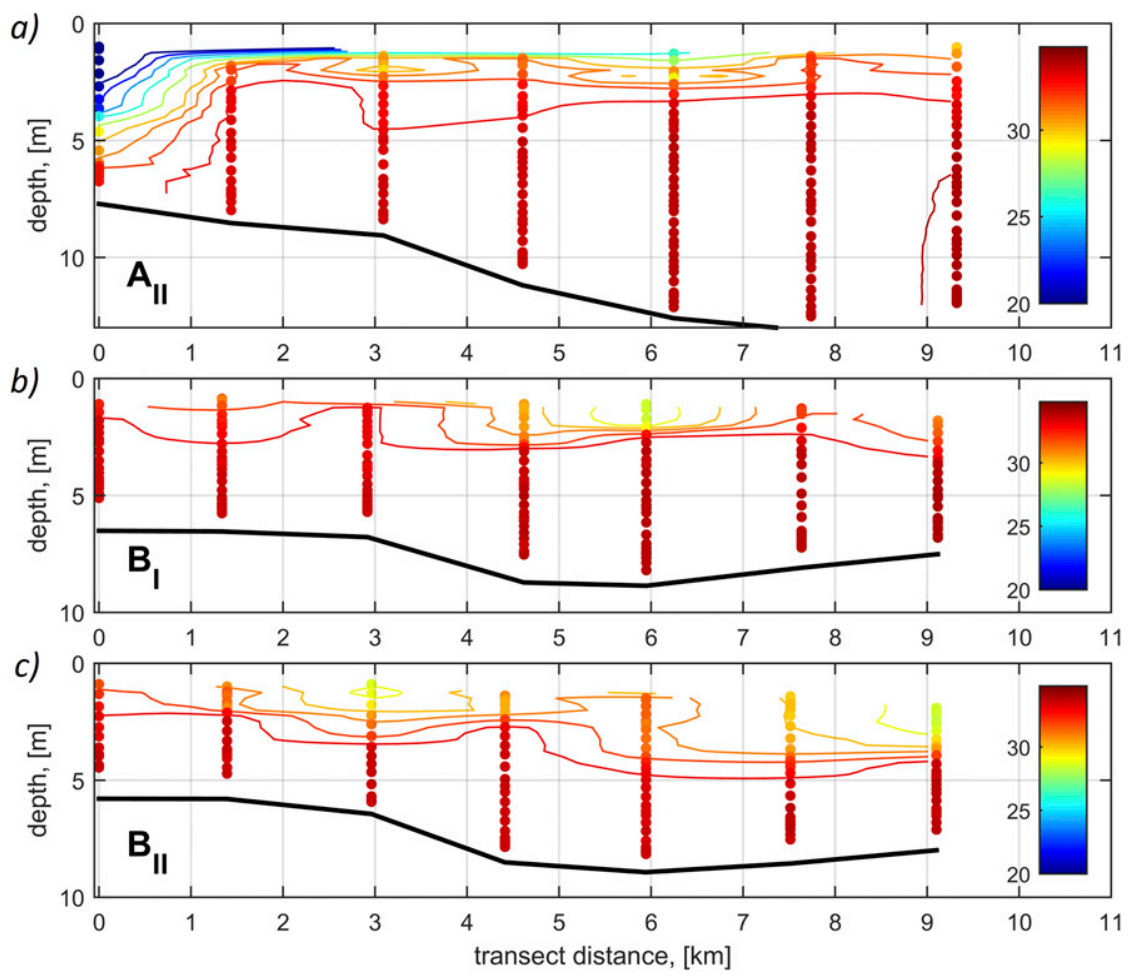

FIG. 7. Vertical transects of binned salinity: (a) $A_{I I}$, (b) $B_{I}$, and (c) $B_{I I}$. Both measured (dots) and interpolated (contours) values are shown; the salinity contours are 20:2:29 and 30:1:34. The heavy black line is the bottom.

black color is also seen in Fig. 1. This image was obtained several hours after the completion of transect $\mathrm{C}$ and confirms an anticyclonic circulation of the discharged freshwater.

Temporal evolution of the plume is delineated by three consecutive salinity transects $\left(\mathrm{A}_{\mathrm{II}}, \mathrm{B}_{\mathrm{I}}\right.$, and $\left.\mathrm{B}_{\mathrm{II}}\right)$ shown in Fig. 7. Initially (following an ebbing tide), the buoyant layer was very shallow, $\sim 2-2.5 \mathrm{~m}$ deep, with a sharp pycnocline (Fig. 7a). On transect $\mathrm{B}_{\mathrm{I}}$, seawater with the lowest salinity was observed at $r=6 \mathrm{~km}$, which implies an anticyclonic flow pattern around the offshore edge of the plume. The plume extended offshore beyond the last station on the transect, and the buoyant layer with minimum salinity had become deeper than on transect $\mathrm{A}_{\mathrm{II}}$. Continuing mixing and offshore spreading of the plume was evident on transect $\mathrm{B}_{\mathrm{II}}$, where the plume further deepened and the low-salinity water was observed at the last station of the transect $(r=9.1 \mathrm{~km}$ in Fig. 7c).

Full offshore extent of the plume from the WB mouth was captured by transect $\mathrm{C}$ (Fig. 8). The plume remained shallow ( $\sim 3-6 \mathrm{~m})$, its $h$ and $s$ both increased offshore, and the increase in $h$ occurred in a steplike manner (at $r \sim 10$ and $16 \mathrm{~km}$ ) rather than continuously. Several stations adjacent to these steps (e.g., C9, C11, and C12) reveal an inverse salinity distribution with depth in binned data, indicative of overturning. Similar overturning features were observed on the previous transects, $\mathrm{A}_{\mathrm{II}}$ in particular: at $r=3.1$ and $6.2 \mathrm{~km}$ (Fig. 7a). Temperature $T$ variations (Fig. 8 b) were relatively small and counteracted the salinity contribution to the density field (i.e., buoyant layer had lower $T$ ). Nevertheless, the $T$ distribution delineates the spatial structure of the plume well (e.g., steplike increase of $h$ ) and confirms vertical inversions. Presence of inversions suggests that mixing occurred not only in the offshore segment of the plume where isopycnals outcropped to the surface but also in its interior. In general, caution should be exercised when inversions in CTD-derived salinity (and density) profiles are interpreted as overturns. Poor temporal synchronization of temperature and conductivity probes (along with their different thermal inertia) can lead to artificial spikes of salinity. However, this is not the case with the presented observations. Seawater was pumped to the CTD sensors at constant rate and the temperature variations with depth were relatively small. In addition, time lag between temperature and conductivity sensors was adjusted to minimize salinity spikes. The observed overturns appear in averaged (binned) data, 

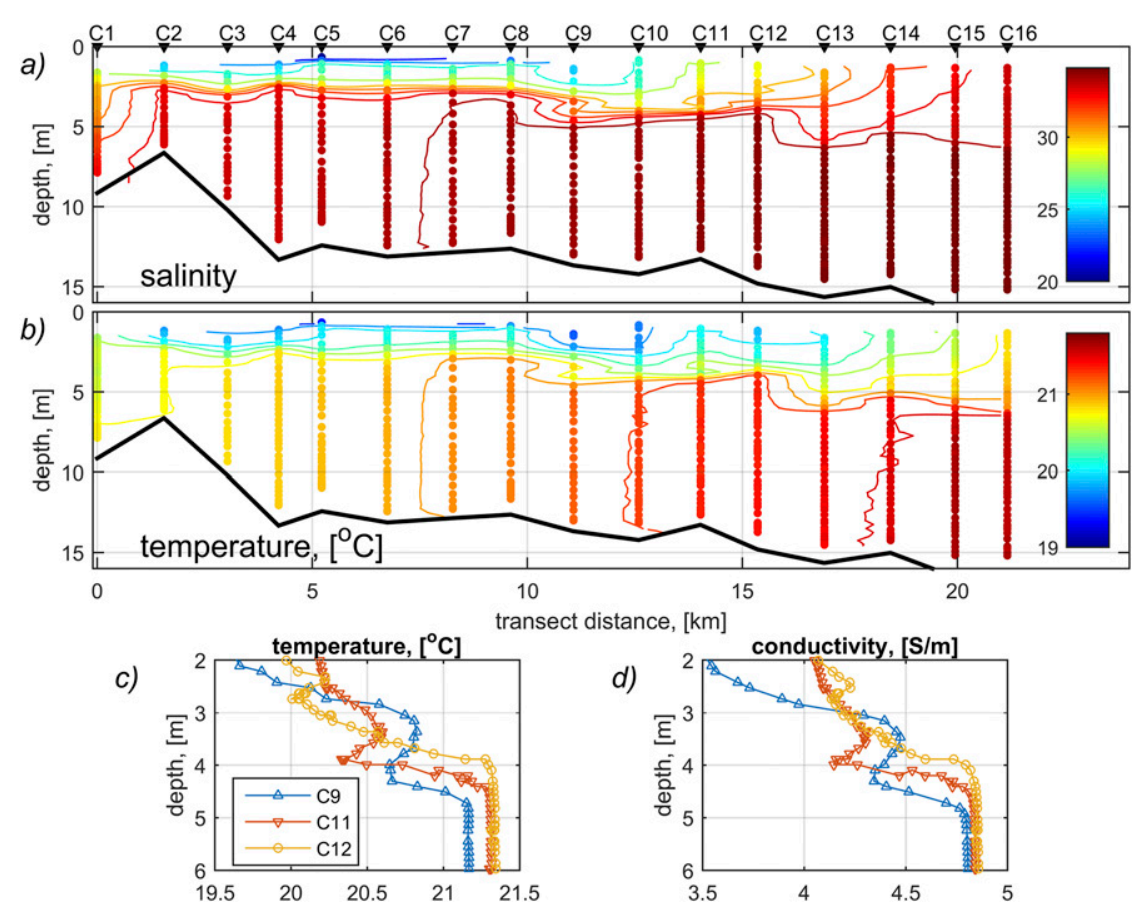

FIG. 8. Vertical transect C, (a) binned salinity, (b) binned temperature, and examples of original profiles of (c) temperature and (d) conductivity. In (a) and (b), both measured (dots) and interpolated (contours) values are shown. Salinity is contoured at intervals of $2(s<30)$ and $1(s>30)$; temperature is contoured at an interval of $0.25^{\circ} \mathrm{C}$. In (c) and (d), original samplings are shown with symbols. The heavy black line is the bottom.

where no individual small spikes are present. To prove that they were real features, we plot original temperature and conductivity profiles, which clearly resolve the overturns characterized by vertical scales of $\sim 1-1.5 \mathrm{~m}$ (Figs. 9c,d). Each overturn was resolved with at least 10 individual samplings or more.

If mixing did occur across the pycnocline, it was associated with Kelvin-Helmholtz type instabilities (e.g., MacDonald and Geyer 2004; Jurisa et al. 2016; Iwanaka and Isobe 2018) and was initiated when the gradient Richardson number $\left[\mathrm{Ri}=(g / \rho) \rho_{z} /\left(u_{z}^{2}+v_{z}^{2}\right)\right]$ was at or below its critical value of 0.25 . Here, $u$ and $v$ are $x$ and $y$ components of the velocity vector, respectively, and subscript refers to the partial derivative with respect to $z$. Ri was estimated along transect $\mathrm{C}$ (Fig. 9) with the density data now averaged in vertical bins identical to those of the ADCP data. To improve the accuracy of the vertical density derivative, the averaged pressure was used for each bin (rather than its nominal depth) so that $d z$ slightly varied around $0.5 \mathrm{~m}$ between different bins. The uppermost estimate of $\mathrm{Ri}$ corresponds to a depth of $3.3 \mathrm{~m}$ (limited by the ADCP

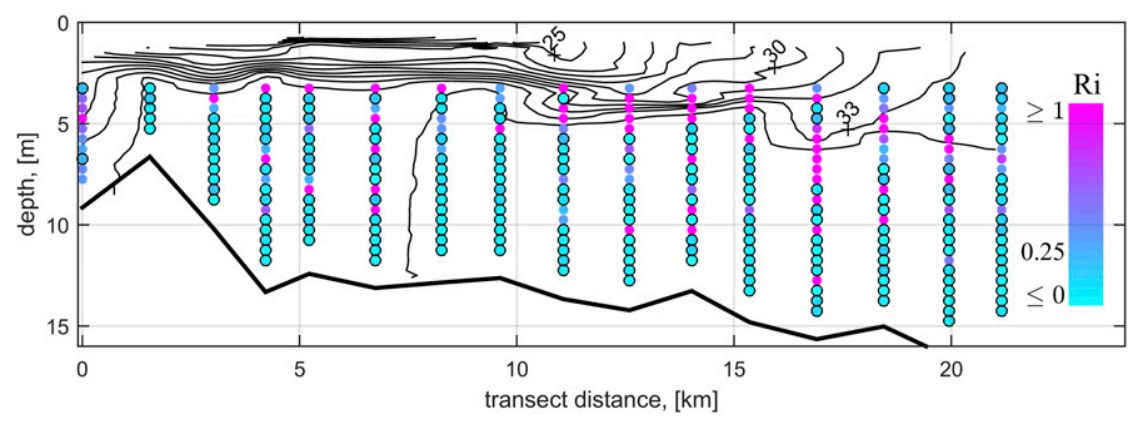

FIG. 9. Vertical transect C, showing Ri (color dots) and salinity (contours with an interval of 1). Subcritical values of $\mathrm{Ri} \leq 0.25$ are highlighted with black-outlined circles. The heavy line is the bottom. 
data binning), which corresponded to the base of the inshore, shallower part of the plume. As predicted by FG01 and L04, the offshore edge of the plume where isopycnals outcrop $(r>17 \mathrm{~km})$ was characterized by near- or subcritical values of Ri. However, subcritical values of $\mathrm{Ri}$ were found also within the pycnocline at two thermohaline steps $(r=11.1$ and $16.9 \mathrm{~km})$, confirming that mixing was not limited to the offshore edge. In addition, there were near-critical values of $\mathrm{Ri}$ within the pycnocline as well as overturns in the density field above the vertical range of $\mathrm{Ri}$ estimates at all stations for $r>8 \mathrm{~km}$ (starting from station C8).

\section{Scaling analysis and interpretation of observations}

Our data reveal that under light upwelling wind forcing, in addition to mixing at the plume's offshore edge (as predicted by FG01 and L04), there are steplike changes of the plume's thickness along radial transects, where vigorous mixing and overturning occur. We hypothesize that each thermohaline step seen on transect $\mathrm{C}$ (and to a lesser degree on transects $\mathrm{B}_{\mathrm{I}}$ and $\mathrm{B}_{\mathrm{II}}$ ) represents a tidal plume front formed after an individual tidal cycle (i.e., every $12.4 \mathrm{~h}$ ) and then advected offshore by Ekman transport.

The schematic in Fig. 10 summarizes our proposed scenario for the bulge formation. Onset of the plume starts with the formation of a tidal plume at $t_{0}$ with associated frontal structure following an ebb cycle. Because of the convergent flow at the front, the buoyantlayer depth attains its maximum here. Subsequently, the tidal plume is advected offshore at the Ekman drift speed, while geostrophic adjustment produces a frontal jet. Entrainment and mixing occur in the frontal zone with outcropping isopycnals (as described by FG01 and L04). Because of ambient water entrainment, the plume deepens and its salinity anomaly decreases. Entrainment also leads to the increase of frontal jet transport, which in turn sustains a local maximum of the buoyant-layer depth at the front. Meanwhile, a new tidal plume forms following a tidal period of $T_{\mathrm{M} 2}$.

The proposed mechanism described above is based on the assumption of light wind forcing, which implies that newly discharged buoyant water can form a front. Frontal flow undergoes a rotational adjustment and ultimately forms a geostrophic jet along the rim of the tidal plume. The formation of this front should not be inhibited by the superimposed wind stress $\tau_{y}$; that is, the Coriolis force associated with the newly discharged buoyant flow should exceed the wind stress forcing applied to the buoyant layer:

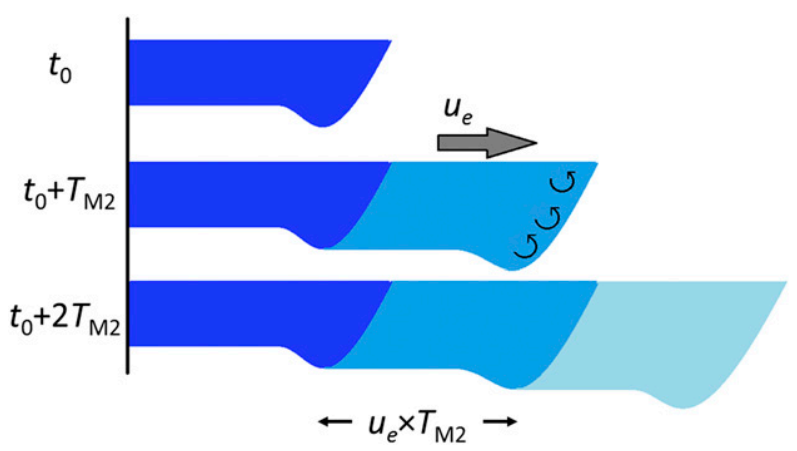

FIG. 10. Schematic of the observed plume formation along a radial transect. $T_{\mathrm{M} 2}$ is the period of dominant tidal harmonic $\mathrm{M} 2$; shading/color intensity is proportional to the salinity anomaly of the plume.

$$
u_{i} f>\frac{\tau_{y}}{\rho_{0} h}
$$

Here, $f$ is the Coriolis parameter, and the inflow velocity $u_{i}$ can be scaled as $u_{i}=\sqrt{g^{\prime} h}$, where $g^{\prime}=g \Delta \rho / \rho_{0}$ is the reduced gravity associated with the buoyant layer. Equivalently, (3) states that the baroclinic velocity in the tidal plume exceeds the depth-averaged speed of the Ekman drift $u_{e}=\tau_{y} /\left(\rho_{0} f h\right)$. Near the source (i.e., stations A1 and U1) during the ebbing tide, $h_{f} \geq 1 \mathrm{~m}$, while $h \approx$ $3 \mathrm{~m}$, which translates into an average buoyant-layer salinity of $\sim 22.5$ or less (assuming ambient water salinity of 234 ). This corresponds to a buoyant-layer density anomaly $\Delta \rho \geq 8.5 \mathrm{~kg} \mathrm{~m}^{-3}$. If we take $\Delta \rho=8.5 \mathrm{~kg} \mathrm{~m}^{-3}$ as the low limit and $\rho_{0}=1020 \mathrm{~kg} \mathrm{~m}^{-3}$, then $u_{i} \approx 0.5 \mathrm{~m} \mathrm{~s}^{-1}$. For the Ekman velocity, we assume $\tau_{y}=0.04 \mathrm{~Pa}, f=9 \times$ $10^{-5} \mathrm{~s}^{-1}$, and again $h=3 \mathrm{~m}$, which yields $u_{e}=0.15 \mathrm{~m} \mathrm{~s}^{-1}$. Hence, $u_{i}$ exceeds $u_{e}$ by a factor of 3 , and the assumption of light wind forcing is clearly satisfied.

The $u_{e}$ estimate translates into a horizontal distance of $\sim 6.5 \mathrm{~km}$ over a $12-\mathrm{h}$ time interval. This distance is close to the separation in the offshore direction between the two pycnocline steps observed at $r=10$ and $16 \mathrm{~km}$ (Fig. 8), while a new tidal plume front was forming at $r=4-5 \mathrm{~km}$ (stations $\mathrm{C} 4$ and C5). The three tidal fronts seen on transect $\mathrm{C}$ are consistent with three ebb events that had occurred by the time of measurements since the onset of the upwelling-favorable wind (Fig. 3b).

We now generalize the definition of conditions favorable for the formation of interior fronts under the proposed scenario. In addition to condition (3), the interior fronts we have described can occur if Ekman transport separates them in space. This requires that the wind-driven offshore excursion of the buoyant layer on the tidal time scale exceeds the cross-shore scale of the front, typically associated with the internal Rossby radius $\mathrm{Rd}$ : 


$$
\frac{u_{e}}{\omega_{\mathrm{M} 2} \mathrm{Rd}} \geq 1,
$$

where $\omega_{\mathrm{M} 2}$ is the M2 tidal frequency. Defining Rossby radius as $\mathrm{Rd}=\sqrt{g^{\prime} h} f^{-1}$, we combine conditions (3) and (4) into a single statement:

$$
\frac{f}{\omega_{\mathrm{M} 2}} \leq \frac{\tau_{y}}{\rho_{0} f\left(g^{\prime} h^{3}\right)^{1 / 2}}<1 .
$$

We would like to relate the buoyant-layer density anomaly (expressed through $g^{\prime}$ ) and depth in (5) to the freshwater discharge $q_{r}$ and the intensity of mixing characterized by the plume salinity anomaly $\Delta s=s_{r}-s$. Assuming that the tidal front achieves a geostrophic adjustment, $h$ can be defined (e.g., Yankovsky and Chapman 1997) as

$$
h=\left(\frac{2 Q f}{g^{\prime}}\right)^{1 / 2},
$$

where $Q=s_{r} q_{r} / \Delta s$ is the net transport in the frontal current, which proportionally increases as the freshwater discharge is mixed with the oceanic water, so that the freshwater transport is conserved. Assuming $\Delta \rho=\gamma \Delta s$ and substituting (6) into (5), we obtain,

$\frac{f}{\omega_{\mathrm{M} 2}} \leq A \frac{\tau_{y} \Delta s}{f^{7 / 4} q_{r}^{3 / 4}}<1, \quad$ where $\quad A=\frac{(g \gamma)^{1 / 4}}{\rho_{0}^{5 / 4}\left(2 s_{r}\right)^{3 / 4}}$.

The parameters in term $A$ exhibit very small variations (typically, within a few percent or less) so that $A$ can be treated as a constant, at least for scaling purposes and within large geographic regions. For the SAB shelf, we select the following representative values: $s_{r}=34, \gamma=$ $0.76 \mathrm{~kg} \mathrm{~m}^{-3}$, and $\rho_{0}=1020 \mathrm{~kg} \mathrm{~m}^{-3}$.

The results are summarized in Fig. 11 for three values of wind stress $(0.03,0.04$, and $0.05 \mathrm{~Pa})$ and for a broad range of both salinity anomalies and freshwater discharge. For each wind stress value, the favorable regime for the interior front formation according to (7) is demarcated by two limits. For $\Delta s$ values greater than those delineated by the right limit (Fig. 11, dashed lines), the individual tidal fronts will be dispersed by the wind stress so that the plume will be homogenized; for $\Delta s$ values smaller than those defined by the left limit (Fig. 11, solid lines), individual tidal fronts will not be separated, but will be blended into one broad frontal zone. In this diagram, we omit low freshwater-discharge values because under such conditions the hypothesis of the rotational adjustment of the buoyant outflow may be violated (e.g., O'Donnell 2010). It is worth noting that strong mixing (low $\Delta s$ ) is not favorable for the interior

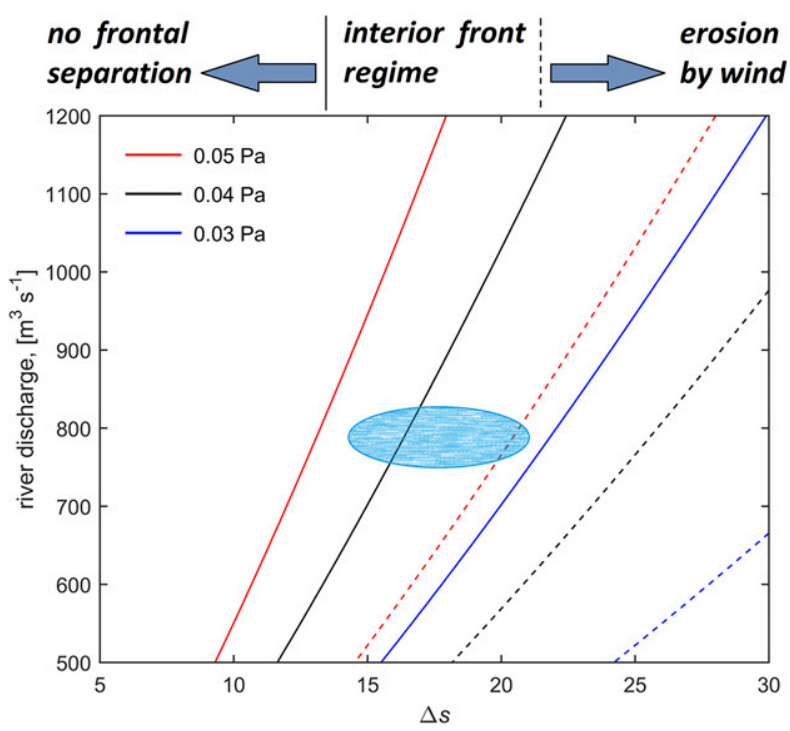

FIG. 11. Favorable conditions for interior-front formation based on the scaling in section 4 [see (7)] and shown for three different wind stresses. Shaded area delineates the conditions encountered during the reported survey off WB (see text for details).

front formation. Also, as the discharge increases, it is the left limit (separation of individual tidal fronts) that determines the existence of the interior fronts. The $\Delta s$ and $q_{r}$ values encountered during our observations (the latter includes the possible contribution of other small rivers, not just the Pee Dee) are also shown in Fig. 11 as a shaded ellipse. It appears that the conditions were quite optimal for the interior front formation when the alongshore wind stress was $0.04-0.05 \mathrm{~Pa}$ (upper limit of its observed values; see Fig. 3).

Next, we address the cause for entrainment and mixing at the foot of the steplike frontal structure. A schematic for the proposed scaling is drawn in Fig. 12a: We assume that newly formed tidal plume 1 is adjacent to the previously existing buoyant plume 2 exposed to the upwelling-favorable wind. In plume 2, the wind-induced mixing regime (as in FG01 and L04) has already been established such that the corresponding $\mathrm{Ri}^{*}$ is near critical. Assuming that for plume $2 \Delta u$ in (1) is determined by $u_{e}$, plume thickness $h_{2}$ can be deduced as (similar to L04),

$$
h_{2}=\left(\frac{\tau_{y}^{2} \mathrm{Ri}_{2}^{*}}{g \Delta \rho_{2} \rho_{0} f^{2}}\right)^{1 / 3} .
$$

In the frontal zone (Fig. 12a), the density anomaly is the average of the two plumes, 1 and 2, while the velocity shear is due to a combination of the offshore Ekman drift and the alongshore geostrophic frontal jet $v_{g}$, thus, 
a)

b)
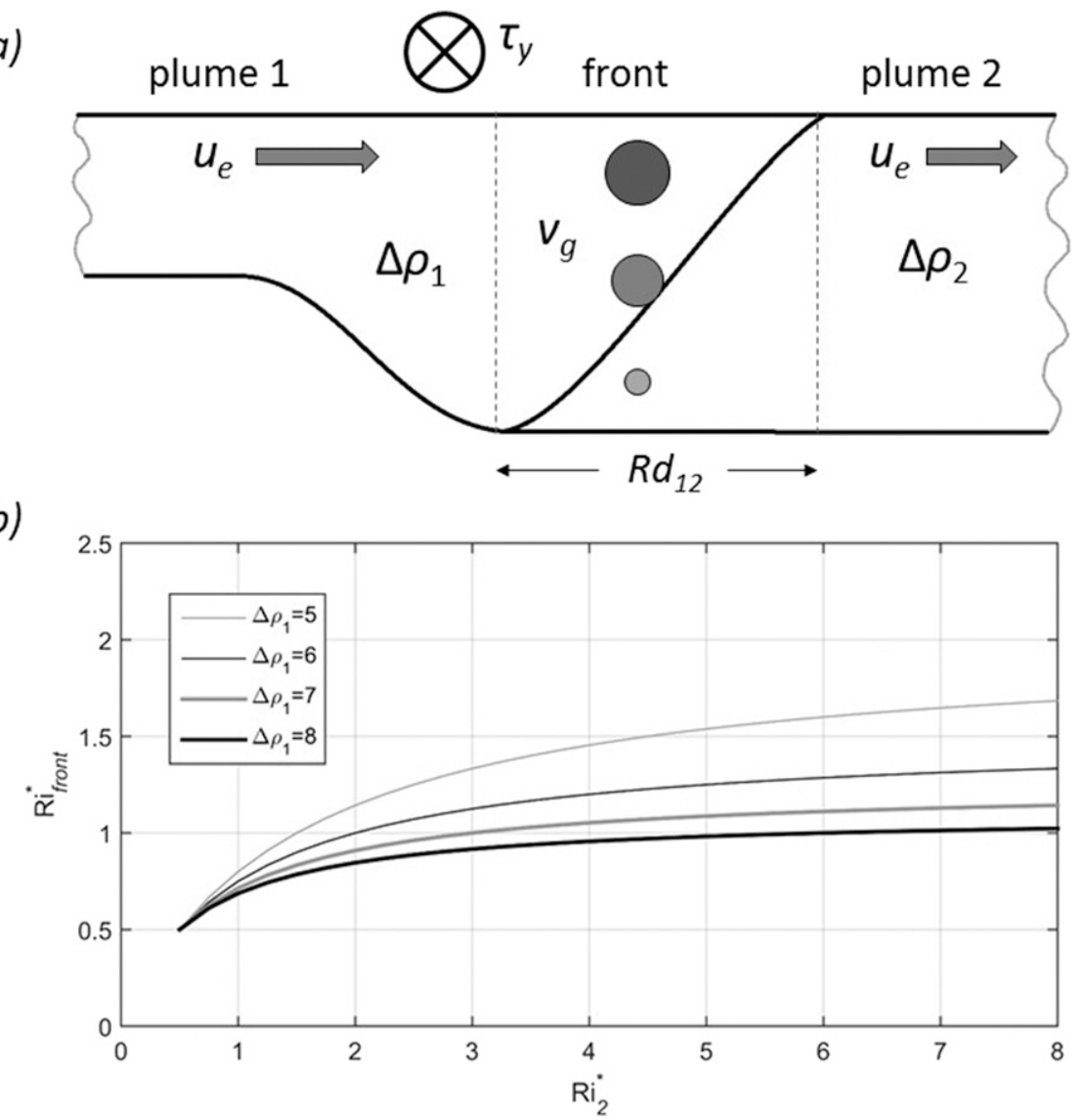

FIG. 12. (a) Schematic of an interior front and (b) dependence of $\mathrm{Ri}^{*}$ in the frontal zone on $\mathrm{Ri}$ * in the offshore plume 2 for different values of $\Delta \rho_{1}$, where $\Delta \rho_{2}$ is set to $3 \mathrm{~kg} \mathrm{~m}^{-3}$.

$$
\mathrm{Ri}_{f}^{*}=\frac{g \Delta \bar{\rho} h_{2}}{\rho_{0}\left(v_{g}^{2}+u_{e}^{2}\right)}
$$

where $\Delta \bar{\rho}=0.5\left(\Delta \rho_{1}+\Delta \rho_{2}\right)$. Since the interface between the two plumes outcrops to the surface, there is ongoing mixing between the two plumes. However, since $h_{1}<h_{2}$ and consequently $u_{e 1}>u_{e 2}$, there is advection of plume 1 water into a front, which sustains sloping isopycnals. We further assume that $v_{g}$ is in thermal wind balance and can be scaled as,

$$
v_{g}=h_{2} \frac{\partial v_{g}}{\partial z}=-\frac{g h_{2}}{f \rho_{0}} \frac{\Delta \rho_{12}}{\operatorname{Rd}_{12}}=-\left(\frac{g \Delta \rho_{12} h_{2}}{\rho_{0}}\right)^{1 / 2} .
$$

Here, $\Delta \rho_{12}=\Delta \rho_{1}-\Delta \rho_{2}$ and $\operatorname{Rd}_{12}$ is the baroclinic Rossby radius associated with the interface between plumes 1 and 2: $\operatorname{Rd}_{12}=\left(g \Delta \rho_{12} h_{2} / \rho_{0}\right)^{1 / 2} f^{-1}$.

Substituting $u_{e}$ and $v_{g}$ into (9) and using (8) for $h_{2}$ yields,

$$
\mathrm{Ri}_{f}^{*}=\frac{\Delta \bar{\rho} \mathrm{Ri}_{2}^{*}}{\Delta \rho_{2}+\Delta \rho_{12} \mathrm{Ri}_{2}^{*}} .
$$

This expression shows that the bulk Richardson number is always smaller in the interior frontal zone than in the adjacent plume 2 lying farther offshore. For instance, for $\mathrm{Ri}_{2}^{*}=1$, (11) is reduced to $\mathrm{Ri}_{f}^{*}=\left(\Delta \rho_{2}+\Delta \rho_{1}\right) / 2 \Delta \rho_{1}<1$. Figure $12 \mathrm{~b}$ gives examples of the $\mathrm{Ri}^{*}$ decrease in the frontal zone according to (11), where $\Delta \rho_{2}=3 \mathrm{~kg} \mathrm{~m}^{-3}$, and several different values of $\Delta \rho_{1}$ are considered. For $\Delta \rho_{1}=8 \mathrm{~kg} \mathrm{~m}^{-3}$ (close to the observed value), $\mathrm{Ri}$ f remains at a near-critical level of $\sim 1$ even when $\mathrm{Ri}_{2}^{*}$ rises to values of 5-7, well above the entrainment regime (which, for instance, can occur because of the fluctuating in time wind stress).

Another interesting feature of the reported observations is that the anticyclonic bulge had a very small depth $(\sim 3-5 \mathrm{~m})$ to width $(\sim 20 \mathrm{~km})$ aspect ratio. There are several previous observational studies reporting formation of anticyclonic bulges with recirculating buoyant flow, notably in the Columbia River plume (e.g., Hickey et al. 1998; Horner-Devine 2009) and in the Hudson River plume (e.g., Chant et al. 2008). The rate of the bulge growth is determined by the fraction of buoyant discharge retained in the recirculating anticyclonic flow. 
However, we argue that in the present case almost all discharge was trapped in the bulge, resulting in the formation of an unusually large bulge over a short period of time. From simple geometric considerations, we can estimate the radius of the anticyclonic bulge $R$ as,

$$
R=\sqrt{\frac{q_{r} T_{p}}{\pi h_{f}}},
$$

where $q_{r}$ is the freshwater discharge feeding the bulge, and $T_{p}$ is the time scale for the bulge formation (i.e., the bulge's age). Assuming $q_{r}=800 \mathrm{~m}^{3} \mathrm{~s}^{-1}, h_{f}=0.6 \mathrm{~m}$ (now it is an average rather than a frontal value), and $T_{p}=$ $36 \mathrm{~h}$ (i.e., three tidal cycles since the relaxation of downwelling-favorable wind event; see Fig. 3) yields $R=7.4 \mathrm{~km}$, or the offshore extension of the bulge of approximately $15 \mathrm{~km}$. Here, we explicitly assume that all the discharged water was trapped in the bulge. This estimate is in close agreement with observations: Although the buoyant layer on transect $\mathrm{C}$ extended offshore for $\sim 20 \mathrm{~km}$, the freshwater content in its outer edge $(16<r<20 \mathrm{~km}$ ) was small (Figs. 6, 8).

\section{Conclusions}

This study reports observations of a buoyant plume bulge off Winyah Bay, South Carolina, which was formed under conditions of high freshwater discharge and upwelling-favorable wind forcing. The wind forcing was light and did not completely suppress the inherent dynamics of the plume, allowing anticyclonic turning and southward flow of the buoyant water. We define light wind conditions based on the dynamic characteristics of the plume that depend on the competition between the buoyancy effect and the wind-induced turbulent stresses.

The observed structure of the bulge differed from theoretical predictions and observations of a far-field response to upwelling-favorable wind. In particular, the coastal source of buoyant discharge precluded the lateral homogenization of the buoyant layer in the manner postulated for a far field by FG01 and L04. Indeed, the cross-shore plume structure captured by transect $\mathrm{C}$ reveals the age of buoyant water: A buoyant layer farther offshore has a smaller salinity signature and larger $h$ because of its longer exposure to the wind-induced mixing.

The plume depth increased from $\sim 3$ m near the mouth to $6 \mathrm{~m}$ at the offshore edge, with plume depth changing in a steplike fashion rather than continuously. CTD profiles near these steps revealed overturning indicative of vigorous mixing. Estimates of gradient Richardson number confirmed the likelihood of mixing/entrainment not only at the offshore edge of the plume but also in the proximity of the observed steps. We hypothesize that these steps represent tidal fronts that subsequently undergo geostrophic adjustment and are advected offshore by the superimposed Ekman drift. This hypothesis is further confirmed by higher values of $h_{f}$ (especially at station C9) associated with pycnocline steps, which indicates a convergent flow regime typical of tidal fronts. Assuming that pycnocline steps represent interior fronts with geostrophic jets, the associated mixing and entrainment can be explained by a superposition of geostrophic and wind-induced shear. The observed fronts differ from previously described interior fronts (e.g., Garvine 1984; Luketina and Imberger 1987) in that their spatial separation is much larger: several kilometers versus $O(10)-O(100) \mathrm{m}$ previously reported, as well as their rotational adjustment (baroclinic flow along the front), which implies a different generation mechanism. According to scaling arguments presented in section 4, the observed interior fronts are expected to be a ubiquitous feature for tidally modulated midlatitude freshwater discharges of $O\left(10^{2}-10^{3}\right) \mathrm{m}^{3} \mathrm{~s}^{-1}$. The possible exception might be estuaries with strong tidal mixing (resulting in small $\Delta s$ values of the buoyant outflow). In the classification scheme proposed by Geyer and MacCready (2014), such buoyancy sources would be well-mixed estuaries and estuaries with strain-induced periodic stratification.

In conclusion, the response of the anticyclonic bulge formed by tidally modulated estuarine outflow to the light upwelling-favorable wind appears to be more complex than the far-field response, which can be fairly accurately described by a slab-like model (FG01; L04). In particular, the bulge region exhibits significant crossshelf variations in its thickness and density anomaly, while mixing is not limited to the offshore edge with outcropping isopycnals.

Acknowledgments. The wind data at the Winyah Bay mouth were collected and graciously provided by the commercial weather network WeatherFlow (https:// weatherflow.com). The seamanship and competent work of the captain and crew of R/V Savannah were critical for the successful completion of this survey. Cruise data are archived at and available from NOAA NCEI (https://doi.org/10.7284/906782). We are indebted to two anonymous reviewers for their insightful comments and suggestions that substantially improved this manuscript. Financial support was provided by the U.S. National Science Foundation (NSF) under RAPID Award OCE-1603957. GV's contribution was with the support of, and while serving at, NSF. Any opinions, findings, and conclusions or recommendations expressed in this study are those of the authors and do not necessarily reflect the views of NSF. 


\section{REFERENCES}

Blanton, B. O., and Coauthors, 2004: Barotropic tides in the South Atlantic Bight. J. Geophys. Res., 109, C12024, https://doi.org/ 10.1029/2004JC002455.

Chant, R. J., S. Glenn, and J. Kohut, 2004: Flow reversals during upwelling conditions on the New Jersey inner shelf. J. Geophys. Res., 109, C12S03, https://doi.org/10.1029/2003JC001941.

,-- E. Hunter, J. Kohut, R. F. Chen, R. W. Houghton, J. Bosch, and O. Schofield, 2008: Bulge formation of a buoyant river outflow. J. Geophys. Res., 113, C01017, https://doi.org/ 10.1029/2007JC004100.

Chen, C., L. Zheng, and J. O. Blanton, 1999: Physical processes controlling the formation, evolution, and perturbation of the low-salinity front in the inner shelf off the southeastern United States: A modeling study. J. Geophys. Res., 104, 1259-1288, https://doi.org/10.1029/1998JC900040.

Fong, D. A., and W. R. Geyer, 2001: Response of a river plume during an upwelling favorable wind event. J. Geophys. Res. 106, 1067-1084, https://doi.org/10.1029/2000JC900134.

Garvine, R. W., 1984: Radial spreading of buoyant, surface plumes in coastal waters. J. Geophys. Res., 89, 1989-1996, https://doi.org/ 10.1029/JC089iC02p01989.

Geyer, W. R., and P. MacCready, 2014: The estuarine circulation. Annu. Rev. Fluid Mech., 46, 175-197, https://doi.org/10.1146/ annurev-fluid-010313-141302.

Hickey, B. M., L. J. Peitrafesa, D. A. Jay, and W. C. Boicourt, 1998 : The Columbia River plume study: Subtidal variability in the velocity and salinity fields. J. Geophys. Res., 103, 10339 10368, https://doi.org/10.1029/97JC03290.

Horner-Devine, A. R., 2009: The bulge circulation in the Columbia River plume. Cont. Shelf Res., 29, 234-251, https://doi.org/ 10.1016/j.csr.2007.12.012.

—- R. D. Hetland, and D. G. MacDonald, 2015: Mixing and transport in coastal river plumes. Annu. Rev. Fluid Mech., 47, 569-594, https://doi.org/10.1146/annurev-fluid-010313141408.

Houghton, R. W., C. E. Tilburg, R. W. Garvine, and A. Fong, 2004: Delaware River plume response to a strong upwellingfavorable wind event. Geophys. Res. Lett., 31, L07302, https://doi.org/10.1029/2003GL018988.

Iwanaka, Y., and A. Isobe, 2018: Tidally induced instability processes suppressing river plume spread in a nonrotating and nonhydrostatic regime. J. Geophys. Res. Oceans, 123, 35453562, https://doi.org/10.1029/2017JC013495.

Jurisa, J. T., J. D. Nash, J. N. Moum, and L. F. Kilcher, 2016: Controls on turbulent mixing in a strongly stratified and sheared tidal river plume. J. Phys. Oceanogr., 46, 2373-2388, https://doi.org/ 10.1175/JPO-D-15-0156.1.

Kim, Y. H., and G. Voulgaris, 2005: Effect of channel bifurcation on residual estuarine circulation: Winyah Bay, South Carolina Estuarine Coastal Shelf Sci., 65, 671-686, https://doi.org/ 10.1016/j.ecss.2005.07.004.
Lentz, S., 2004: The response of buoyant coastal plumes to upwelling-favorable winds. J. Phys. Oceanogr., 34, 2458-2469, https://doi.org/10.1175/JPO2647.1.

- and J. Largier, 2006: The influence of wind forcing on the Chesapeake Bay buoyant coastal current. J. Phys. Oceanogr., 36, 1305-1316, https://doi.org/10.1175/JPO2909.1.

Luketina, D. A., and J. Imberger, 1987: Characteristics of a surface buoyant jet. J. Geophys. Res., 92, 5435-5447, https://doi.org/ 10.1029/JC092iC05p05435.

MacDonald, D. G., and W. R. Geyer, 2004: Turbulent energy production and entrainment at a highly stratified estuarine front. J. Geophys. Res., 109, C05004, https://doi.org/10.1029/ 2003JC002094.

- L. Goodman, and R. D. Hetland, 2007: Turbulent dissipation in a near-field river plume: A comparison of control volume and microstructure observations with a numerical model. J. Geophys. Res., 112, C07026, https://doi.org/ 10.1029/2006JC004075.

Meyer, J. L., 1990: A blackwater perspective on riverine ecosystems. BioScience, 40, 643-651, https://doi.org/10.2307/1311431.

Münchow, A., and R. W. Garvine, 1993: Buoyancy and wind forcing of a coastal current. J. Mar. Res., 51, 293-322, https:// doi.org/10.1357/0022240933223747.

O'Donnell, J., 2010: The dynamics of estuary plumes and fronts. Contemporary Issues in Estuarine Physics, A. Valle-Levinson, Ed., Cambridge University Press, 186-246.

Orton, P. M., and D. A. Jay, 2005: Observations at the tidal plume front of a high-volume river outflow. Geophys. Res. Lett., 32, L11605, https://doi.org/10.1029/2005GL022372.

Sanay, R., A. Yankovsky, and G. Voulgaris, 2008: Inner shelf circulation patterns and nearshore flow reversal under downwelling and stratified conditions off a curved coastline. J. Geophys. Res., 113, C08050, https://doi.org/10.1029/2007JC004487.

Whitney, M. M., and R. W. Garvine, 2005: Wind influence on a coastal buoyant outflow. J. Geophys. Res., 110, C03014, https:// doi.org/10.1029/2003JC002261.

Wu, H., B. Deng, R. Yuan, J. Hu, J. Gu, F. Shen, J. Zhu, and J. Zhang, 2013: Detiding measurement on transport of the Changjiang-derived buoyant coastal current. J. Phys. Oceanogr., 43, 2388-2399, https://doi.org/10.1175/JPO-D-12-0158.1.

Xing, J., and A. M. Davies, 1999: The effect of wind direction and mixing upon the spreading of a buoyant plume in a non-tidal regime. Cont. Shelf Res., 19, 1437-1483, https://doi.org/ 10.1016/S0278-4343(99)00025-4.

Yankovsky, A. E., 2003: The cold water pathway during an upwelling event on the New Jersey shelf. J. Phys. Oceanogr., 33, 1954-1966, https://doi.org/10.1175/1520-0485(2003)033<1954: TCPDAU $>2.0 . \mathrm{CO} ; 2$.

, and D. C. Chapman, 1997: A simple theory for the fate of buoyant coastal discharges. J. Phys. Oceanogr., 27, 13861401, https://doi.org/10.1175/1520-0485(1997)027<1386: ASTFTF $>2.0 . \mathrm{CO} ; 2$. 